remission reduced organ damage. LLDAS on treatment $>50 \%$ of the time, which led to a 50\% reduction in organ damage, is an easier goal to achieve (3 times more person-months observed in our cohort) and more realistic as a clinical trial outcome.

Acknowledgements The Hopkins Lupus Cohort is funded by NIH AR 43727 and NIH AR 69572.

\section{CS-29 CREATION OF A WEIGHTED SLICC SLE CLASSIFICATION CRITERIA AND COMPARISON WITH OTHER SLE CLASSIFICATION CRITERIA}

${ }^{1}$ Michelle Petri* ${ }^{1}$ 'Daniel Goldman, ${ }^{2}$ Laurence S Magder. 'Johns Hopkins University School of Medicine, Baltimore, MD, USA; ${ }^{2}$ University of Maryland, Baltimore, MD USA

\subsection{6/lupus-2018-Ism.64}

Background In previous validation work, the SLICC 2012 SLE classification criteria were more sensitive than the revised ACR-11 criteria, while both criteria had similar agreement with physician diagnoses. Both of these classification rules count each SLE manifestation equally. Our objective was to derive and test a classification rule which differentially weights the variable used in the SLICC classification rule. We also compared this rule to a recently proposed EULAR/ACR classification rule that also uses a weighted approach. [Costenbader $\mathrm{KH}$, Johnson S, Aringer M. EULAR/ACR Classification Criteria Update for SLE. Presented at the 2017 ACR/ARHP Annual Meeting, San Diego CA, November 4-8, 2017].

Methods The physician-rated patient scenarios used to develop the 2012 SLICC classification criteria were re-employed to devise a weighted classification rule. A multiple linear regression model was constructed with the 2012 SLICC criteria variables as predictors and the binary outcome (physician classification of SLE) as the outcome. Weights for each criteria were generated by multiplying each criteria's coefficient by 100 and rounding to the nearest integer. The 'Direct Coombs' criteria was deleted for simplicity. Weights for remaining manifestations were: acute cutaneous (26), chronic cutaneous (12), oral ulcers (16), arthritis (9), serositis (16), renal without biopsy (9), neurologic (9), hemolytic anemia (1), leukopenia or lymphopenia (14), thrombocytopenia (15), alopecia (9), ANA (17), anti-dsDNA (19), anti-Sm (16), antiphospholipid antibodies (8), low complement (11). Classification cutoff was the score that maximized overall agreement (i.e., the sum of sensitivity and specificity) of the new weighted criteria with physician diagnosis. Patients with lupus nephritis or the new weighted classification rule of 56 or more with at least one clinical component and one immunologic component were classified as SLE. We evaluated the performance of this revised SLICC criteria on an independent set of patient scenarios and compared this to the performance of the older revised ACR criteria, the previous SLICC 2012 criteria, and the newly proposed EULAR/ACR criteria.

Results Table 1 shows the performance of the four classification rules. There was no statistically significant difference between any pair of rules with respect to overall agreement with the physician diagnosis.

Conclusions The two newly derived weighted classification rules did not perform better than the existing list-based rules in terms of over-all agreement. Since the list-based rules are easy to calculate, they may be preferred in most clinical settings.
Abstract CS-29 Table 1 Sensitivity and specificity of four different SLE classification rules based on physician diagnoses of patient scenarios

\begin{tabular}{llll}
\hline Classification Rule & $\begin{array}{l}\text { Sensitivity } \\
(\mathrm{n}=349)\end{array}$ & $\begin{array}{l}\text { Specificity } \\
(\mathrm{n}=341)\end{array}$ & $\begin{array}{l}\text { Overall Agreement } \\
(\mathrm{n}=690)\end{array}$ \\
\hline Revised ACR-11 & $290(83 \%)$ & $326(96 \%)$ & $616(89 \%)$ \\
SLICC 2012 & $340(97 \%)$ & $288(84 \%)$ & $628(91 \%)$ \\
Proposed EULAR/ACR & $317(89 \%)$ & $302(90 \%)$ & $619(90 \%)$ \\
$\begin{array}{l}\text { Weighted SLICC 2012 } \\
\text { criteria }\end{array}$ & $310(88 \%)$ & $304(89 \%)$ & $614(89 \%)$ \\
\hline
\end{tabular}

Acknowledgements Presented on behalf of SLICC. The Hopkins Lupus Cohort is funded by NIH AR 43727 and NIH AR 69572.

\section{CS-30 SLEEP DISTURBANCES AMONG WOMEN WITH SYSTEMIC LUPUS ERYTHEMATOSUS (SLE)}

${ }^{1}$ Patricia Katz*, ${ }^{2}$ Sofia Pedro, ${ }^{2,3}$ Kaleb Michaud. ${ }^{1}$ University of California San Francisco; ${ }^{2}$ Forward/National Data Bank for Rheumatic Diseases; ${ }^{3}$ University of Nebraska Medical Center

\subsection{6/lupus-2018-Ism.65}

Background Sleep disturbances (SD) are reported to be common in SLE, but relatively few studies have addressed the issue. We examined the frequency and severity of self-reported SD among individuals with SLE and predictors of SD.

Methods Data were from the National Data Bank for Rheumatic Diseases (NDB), for which participants complete questionnaires every 6 months. In one questionnaire, items about the presence of physician-diagnosed obstructive sleep apnea (OSA) and restless-leg syndrome (RLS), symptoms of OSA and RLS, and the Medical Outcomes Study Sleep Scale (MOS-S) were included. The MOS-S yields 5 subscales; results are shown here only for one (Sleep Problems Index I, SPI-I). Frequencies of reports of OSA, RLS, and RLS symptoms were tabulated. Multivariate regression analyses identified independent predictors of OSA and RLS (logistic regression) and SPI-I scores (linear regression). Potential predictors included age, race, education, smoking, Rheumatic Disease Comorbidity Index (RDCI), ${ }^{1}$ asthma, obesity (BMI $\geq 30 \mathrm{~kg} / \mathrm{m}^{2}$ ), disease duration, pain, prednisone and other medication use, and disease activity (Systemic Lupus Activity Questionnaire, SLAQ ${ }^{2}$ ) and damage (Brief Index of Lupus Damage, BILD ${ }^{3}$ ).

Results Subjects $(n=362)$ were mean age $61 \pm 13$ years and had SLE duration of $26 \pm 13$ years. $23 \%$ reported physician-diagnosed OSA and 20\% RLS, compared to $\sim 2 \%-4 \%$ and $\sim 10 \%$, respectively, in the general population. $18 \%$ and $34 \%$ had symptoms of OSA and RLS, respectively. Mean SPI-I was 39.6 $( \pm 20.2),>0.5$ standard deviation higher (worse) than a population mean. Independent predictors of diagnosed OSA were greater age, obesity, asthma, RDCI, and disease activity (table 1). Predictors of RLS symptoms were RDCI and disease activity (table 1). Worse scores on SPI-I were associated with younger age, low education, higher RDCI, smoking, and greater pain and disease activity (table 1 ).

Conclusion Both OSA and RLS were more common in SLE than in the population; SPI-I scores were also worse. Some predictors of SDs were similar to predictors in the population (age, obesity), but disease activity was also associated with SD. 


\begin{tabular}{|c|c|c|c|}
\hline & $\begin{array}{l}\text { Obstructive Sleep } \\
\text { Apnea }(\mathrm{OSA})^{*} \\
\text { diagnosis }\end{array}$ & $\begin{array}{l}\text { Restless Leg } \\
\text { Syndrome (RLS)* } \\
\text { symptoms }\end{array}$ & $\begin{array}{l}\text { Sleep Problems } \\
\text { Index I (SPI-I)† }\end{array}$ \\
\hline Age, years & $1.04(1.01,1.07)$ & (ns) & $-0.2(0.01)$ \\
\hline White race & (ns) & (ns) & $-6.4(0.02)$ \\
\hline $\begin{array}{l}\text { Low education } \\
\text { (<high school) }\end{array}$ & (ns) & (ns) & $6.4(0.004)$ \\
\hline Smoking, ever & (ns) & (ns) & $4.6(0.03)$ \\
\hline Obesity & $4.6(2.4,8.8)$ & (ns) & (ns) \\
\hline Asthma & $2.5(1.1,5.7)$ & (ns) & (ns) \\
\hline $\mathrm{RDCl}(0-9)$ & $1.3(1.1,1.5)$ & $1.3(1.1,1.5)$ & $1.3(0.02)$ \\
\hline Pain rating $(0-10)$ & (ns) & (ns) & $1.5(0.002)$ \\
\hline \multicolumn{3}{|l|}{ (SLAQ) } & $0.9(<0.0001)$ \\
\hline $\begin{array}{l}\text { * Tabled values are } \\
\dagger \text { Tabled values ar } \\
\text { reflect greater sleep } \\
\text { All regression mod } \\
\text { current asthma, Rh } \\
\text { disease damage (BI }\end{array}$ & $\begin{array}{l}\text { ds ratio }(95 \% \mathrm{Cl}) \text { fr } \\
\text { eta ( } \mathrm{p} \text {-value) from } \\
\text { oblems } \\
\text { include age, race, ec } \\
\text { latic Disease Comork } \\
\text { and disease activit }\end{array}$ & $\begin{array}{l}\text { multiple logistic regr } \\
\text { ple linear regressior } \\
\text { tion, ever smoking, } \\
\text { y Index (RDCl), pred } \\
\text { AQ) }\end{array}$ & $\begin{array}{l}n \text { analyses } \\
\text { alysis. Higher score } \\
\text { ity (BMI } \geq 30 \text { ), con } \\
\text { le dose, pain rating }\end{array}$ \\
\hline
\end{tabular}

Research in SLE has linked SDs to worse outcomes. Previous research in other conditions suggests that SDs might also be a cause of increased disease activity through heighted inflammation. Further research is needed to tease out disease-specific causes and effects of SD in SLE.

\section{REFERENCES}

1. England BR. Arthritis Care Res 2015;6:865.

2. Karlson EW. Lupus 2003;12:280.

3. Yazdany J. Arthritis Care Res 2011;63:1170.

\section{CS-31 SAFETY OF HYDROXYCHLOROQUINE WITHDRAWAL IN OLDER ADULTS WITH SYSTEMIC LUPUS ERYTHEMATOSUS} ${ }^{2}$ Anca Askanase, ${ }^{3}$ Jane E Salmon, ${ }^{3}$ Michael D Lockshin, ${ }^{1}$ Jill P Buyon. ${ }^{1}$ New York University School of Medicine, USA; ${ }^{2}$ Columbia University College of Physicians and Surgeons, USA; ${ }^{3}$ Hospital for Special Surgery, USA

\subsection{6/lupus-2018-Ism.66}

Background Although hydroxychloroquine (HCQ) is a mainstay of treatment for patients with Systemic Lupus Erythematosus (SLE), ocular toxicity can result from accumulated exposure. The introduction of highly sensitive tools has engendered even more concern. As the longevity of patients with SLE improves, additional data will help physicians accurately balance the risk of ocular toxicity and the risk of disease flare, especially in older patients who have stable/quiescent disease. Accordingly, this study was initiated to examine the safety of HCQ withdrawal in older SLE patients.

Methods Data were obtained by retrospective chart review at three lupus centers. Twenty-seven patients met the following inclusion criteria: $\geq 4$ ACR criteria, disease duration $\geq 5$ years, HCQ use of $200-400 \mathrm{mg}$ per day $\geq 5$ years, and discontinuation of hydroxychloroquine at $\geq$ age 55 years. The comparator group comprised 39 age, gender and racial/ethnic matched patients who remained on HCQ. The primary outcome was a clinically meaningful flare within one year of HCQ withdrawal, defined as moderate or severe, using a revised version of the SELENA-SLEDAI Flare composite that separates mild from moderate flares, evaluates each organ system separately, and incorporates increases in corticosteroid dose and/or addition of immunosuppressive agents. Mild flares were considered secondary outcomes.

Results Demographics are provided in table 1. There was a trend toward longer disease duration in the HCQ withdrawal group but no difference in prevalence of prior lupus nephritis between the groups. The reasons for HCQ withdrawal were maculopathy $(\mathrm{n}=13)$, presumed/biopsy proven cardiomyopathy $(n=2)$, patient request $(n=4)$, and miscellaneous other reasons $(n=8)$. There was no difference in the primary or secondary outcomes between the groups (table 1). Two patients had a moderate flare after discontinuing HCQ, of whom one had arthritis treated with methotrexate and one had thrombocytopenia $(>30 \mathrm{~K}$ ) and proteinuria of $2 \mathrm{grams} / \mathrm{d}$ (baseline $700 \mathrm{mg}$ ). Three patients had severe flares while continuing HCQ, of whom two were hospitalized, one for seizures and one for pericarditis; the third had worsening nephritis (urinary protein $>4 \mathrm{~g} / \mathrm{d}$, requiring treatment). Two patients had moderate flares while remaining on HCQ, one of whom had a rash and arthritis treated with tofacitinib and one a rash treated with prednisone.

Conclusions In this retrospective study of older patients with SLE on long-term HCQ, withdrawal did not increase the risk of moderate or severe flares. These data provide reassurance regarding the safety of withdrawing HCQ in stable older SLE patients.

\begin{tabular}{llll} 
Abstract CS-31 Table 1 & & \\
\hline & $\begin{array}{l}\text { HCQ } \\
\text { Withdrawal } \\
(\mathbf{n}=27)\end{array}$ & $\begin{array}{l}\text { HCQ } \\
\text { Continuation } \\
(\mathbf{n}=39)\end{array}$ & P value \\
& 59.9 & 60.6 & 0.52 \\
\hline Age & $92.6 \%$ & $97.4 \%$ & 0.56 \\
Gender (\% Female) & & & 0.78 \\
Race/Ethnicity & $33.3 \%$ & $35.9 \%$ & \\
White & $29.6 \%$ & $25.6 \%$ & \\
Black & $18.5 \%$ & $20.5 \%$ & \\
Hispanic & $18.5 \%$ & $17.9 \%$ & \\
Asian & 26.7 & 21.1 & 0.088 \\
Duration of SLE (years) (n=61) & 19.3 & 17.6 & \\
Duration of HCQ Use (years) $(\mathrm{n}=52)$ & $12(44.4 \%)$ & $13(33.3 \%)$ & 0.44 \\
Prior Renal Disease (N,\%) & $2(7.4 \%)$ & $5(12.8)$ & 0.69 \\
Moderate/Severe Flares (N,\%) & $2(7.4 \%)$ & $2(5.1 \%)$ & \\
Moderate Flare & $0(0 \%)$ & $3(7.7 \%)$ & \\
Severe Flare & $5(18.5 \%)$ & $3(7.7 \%)$ & 0.26 \\
Mild Flare & $7(25.9 \%)$ & $8(20.5 \%)$ & 0.77 \\
\hline All Flares & & & \\
\hline
\end{tabular}

\section{CS-32 SLE-YPLL (YEARS OF POTENTIAL LIFE LOST) AS A MEASURE OF RELATIVE BURDEN OF PREMATURE MORTALITY}

Eric Y Yen, Ram R Singh ${ }^{*}$. University of California at Los Angeles (UCLA), Los Angeles, USA

\subsection{6/lupus-2018-Ism.67}

Background Disease burden is the impact of a health problem on a given area, which can be used to prioritize actions in health, assess performance of healthcare and disease management, identify high-risk populations, and set research 